\title{
Study of Passive Protective Net Protecting the Rockfall Caused by Open-Pit Blasting on High and Steep Slope
}

\author{
Zhiyu Zhang $\mathbb{D}^{1,2}$ Qingyun Qian ${ }^{1}{ }^{1}{ }^{1}$ Jianguo Wang $\mathbb{D}^{1,},{ }^{1,2}$ Haoshan Liu, ${ }^{1}$ Ke Liang, ${ }^{1}$ Zhuo Li, \\ and Guoyin Liu ${ }^{3}$ \\ ${ }^{1}$ Faculty of Land and Resources Engineering, Kunming University of Science and Technology, Kunming, Yunnan, China \\ ${ }^{2}$ Yunnan Key Laboratory of Sino-German Blue Mining and Utilization of Special Underground Space, \\ Kunming University of Science and Technology, Kunming, Yunnan, China \\ ${ }^{3}$ Kunming Kunze Mining Technology Co., Ltd., Kunming, Yunnan, China
}

Correspondence should be addressed to Jianguo Wang; wangjg0831@163.com

Received 6 August 2021; Revised 12 October 2021; Accepted 12 October 2021; Published 25 October 2021

Academic Editor: Shaofeng Wang

Copyright ( 2021 Zhiyu Zhang et al. This is an open access article distributed under the Creative Commons Attribution License, which permits unrestricted use, distribution, and reproduction in any medium, provided the original work is properly cited.

In order to prevent rockfall caused by open-pit blasting on the high and steep slope and ensure that the passive protective net structure has sufficient impact resistance, the mechanism of blasting flyrock causing rockfall is analyzed by using ANSYS/ AUTODYN to establish the model of rockfall and passive protective net; at the same time, the influences of protective net size, rockfall kinetic energy, and rockfall size to the protective effect were also studied. The results show that under the condition of the same rockfall kinetic energy and rockfall size, the larger the size of the protective net, the longer the buffer time, and the impact force that net can sustain is greater; by assuming the protective net size and rockfall size to be a constant, the greater the rockfall kinetic energy, the less the interaction time between rock and net, and the greater the impulse force that net can suffer; similarly, by keeping the protective net size and the kinetic energy of rockfall to be a constant, it is found that the larger the size of the rockfall, the larger the interaction area and longer interaction time with the net, and the less net will be disrupted; the protective net used in the mine can intercept the rockfall caused by flyrock in blasting process effectively and ensure the safety of villager at the foot of the mountain.

\section{Introduction}

Rockfall is a dynamic evolutionary process in which the individual rockmass moves to the bottom of the slop and stops at a flat zone or is crushed under the action of gravity. This rockmass moves rapidly toward the bottom of a slope in several forms, including slipping, rolling, jumping, dropping, and rebound [1]. During the slope engineering construction, according to the geological conditions, the strength of lithology, and the complexity of the environment, the nonexplosive rock breaking technology [2] and controlled blasting technology will produce rolling stone.

The movement of rockfall has the characteristics of variability and randomness, making the prevention of the rockfall difficult. In recent years, there have been many accidents caused by rockfall in open-pit mines. In the middle of the last century, some European and American countries carried out research on the mechanism, safety evaluation, methods, and technologies of protection of rockfall [3]. For the first time, Bozzolo and Pamini [4] conducted numerical simulations of the path and impact characteristics of rockfall. Peila et al. [5] analyzed the energy consumption of rockfall and the deformation of the protective net by studying the collision between rockfall and passive protective net. Thornton et al. [6] studied the restitution coefficient in the normal direction. Cazzani et al. [7] studied the passive protection system concerning rockfall impact using the numerical simulation method and analyzed the relating parameters. Gottardi and Govoni [8] analyzed the deformation and energy absorption of the passive protective net through field experiments. Spadari et al. [9] investigated the factors affecting the loading capacity of the structure of 
the net using the numerical simulation method. At the end of the last century, flexible protection technology has been widely used in many fields, such as mining, railway, hydropower construction, and others [10]. In China, $\mathrm{Hu}$ [11] carried out the earliest research on the movement of rockfall. Zhou and Yang [12] studied the SNS flexible protection system for slope's geological disasters for the first time. Wang et al. [13] studied the influence of the protective cable clips on the effect of the protective net by the ANSYS. Ye et al. [14] summarized the velocity calculation method of perilous rock with different forms of movement and deduced the changing rules of the blasting flyrock's velocity after impacting with the slope. Xu et al. [15] constructed a free-rolling model of rockfall according to the law of energy conservation and obtained the horizontal moving distance after the rockfall impacting with the slope surface. Huang et al. [16] put forward an innovative method of dynamic risk analysis and verified it by taking Shenxianju scenic spot as an example. Under the framework of contact mechanics and rigid body dynamics, $\mathrm{Xu}$ et al. [17] proposed a three-dimensional model to perform rockfall trajectory analysis for rockfall and topography of arbitrary shape. Through the establishment of a three-dimensional finite element model, Yan et al. [18] studied the dynamic response of a typical flexible rockfall guardrail under the impact of different positions; the results show that the impact of different positions has a significant impact on the peak force of uphill anchor cable, resulting in unsafe anchor design. Zhao et al. [19] proposed a flexible ring guardrail model using the discrete element method (DEM).

The blasting area of the MALU phosphate mine, Huize County, Yunnan Province, is located in a high and steep hillside. The strike of blasting area is about $45^{\circ}$ east to north, and the southeast slope is a natural slope with a slope of about $45^{\circ}$. The height difference between the natural slope and the blasting area is about $500 \mathrm{~m}$, and the horizontal distance between them is about $500 \mathrm{~m}$. The southwest side of the blasting area is adjacent to scattered households, and the surrounding environment is shown in Figure 1. Because the flyrock is inevitable to be formed in blasting mining or secondary crushing of large hard rock mass [20], the southeastern side of the mine has been covered by passive protective nets ranging from $50 \mathrm{~m}$ to $100 \mathrm{~m}$ in height according to the terrain in order to prevent rockfall from rolling down along the hillside and affecting the normal life of villagers at the foot of the hill. The specific situation is shown in Figure 2.

Based on the basic assumption below, the velocity of the rockfall impacting the protective net was calculated based on the initial tossed velocity calculated by blasting flyrock experimentally and theoretically. At the same time, numerical simulation was adopted to investigate the collision between the rockfall and protective net and verify the reliability of the mine protective net.

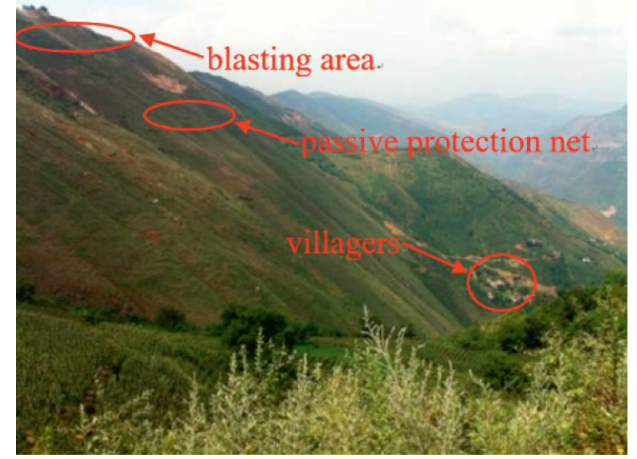

FIGURE 1: Surrounding environment of the blasting area.

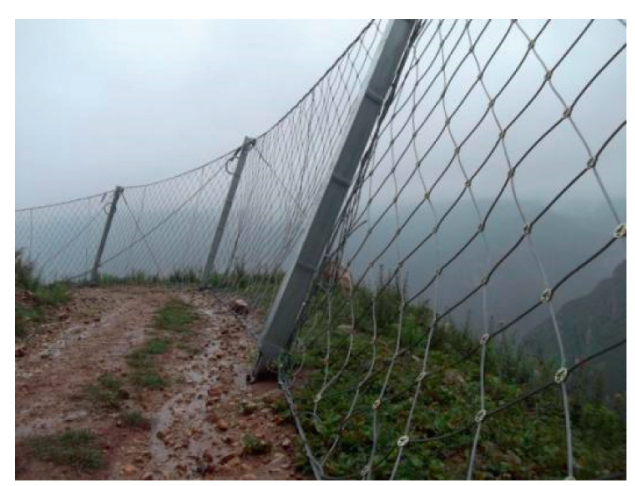

Figure 2: Passive protective net.

\section{The Basic Assumptions of Rockfall's Movement}

Blasting flyrock is one of the most common disasters in open-pit production. The rockfall formed by blasting flyrock has the characteristics of fast velocity, randomness, and complex forms and process of movement. Considering the difficulty on research, the following assumptions about the movement of the rockfall were made:

(1) The air resistance is ignored

(2) Rockfall collides head-on with the protective net under gravity

(3) The collision between blasting generated flying stones is not considered

(4) The second fragmentation effect of the rockfall during the collision between the rockfall or the collision between the rockfall and the slope is ignored

(5) Slope profile is known, and the slope equation is $f(x, y)=0$

(6) Because the step height is relatively small compared with the overall height of the natural slope, the influence of the step height is ignored 
(7) The normal restitution factor and the tangential restitution factor of the collision between the rockfall and the slope are $R_{n}$ and $R_{t}$, respectively

(8) The initial movement state of the rockfall is known

(9) The shape of the rockfall is simplified to a sphere, and the position where the rockfall collides with the protective net is set as the center of the net

\section{The Analysis of Rockfall's Movement}

3.1. Velocity Analysis of Blasting Particles. It is assumed that the flyrock flies out from the coordinate of origin through horizontal velocity $v_{o x}$ and vertical velocity $v_{o y}$, respectively, as shown in Figure 3.

The position of contact between the blasting flyrock and the slope surface is given by the following equation:

$$
\left\{\begin{array}{l}
x=\frac{2 v_{o x}^{2}}{g}\left(\tan \beta-\frac{v_{o y}}{v_{o x}}\right), \\
y=\frac{2 v_{o x}^{2}}{g}\left(\tan ^{2} \beta-\frac{\tan \beta \cdot v_{o y}}{v_{o x}}\right) .
\end{array}\right.
$$

The slope angle was set as $\beta$. According to the field investigation, the slope angle $\beta$ on the southeast side of the mine was $45^{\circ} \sim 60^{\circ}$, and $\beta$ was set as $50^{\circ}$ in the study.

After decomposing $v_{i}$ into tangential velocity $v_{i t}$ that is parallel to the slope and normal velocity $v_{i n}$ that is perpendicular to the slope, the following relationship can be obtained by vector derivation:

$$
\left\{\begin{array}{l}
v_{i t}=v_{i x} \cdot \cos \beta+v_{i y} \cdot \sin \beta, \\
v_{i n}=-v_{i x} \cdot \sin \beta+v_{i y} \cdot \cos \beta .
\end{array}\right.
$$

After the blasting flyrock collides with the slope, it is assumed that the normal incident velocity and the tangential incident velocity are, respectively, $v_{i n}$ and $v_{i t}$; their reflected velocity is, respectively, $v_{o n}$ and $v_{o t}$. Then, the relationship between the velocity before and after the collision can be expressed by the normal restitution factor $R_{n}$ and tangential restitution factor $R_{t}$, which can be solved by the following equation:

$$
\left\{\begin{array}{l}
R_{n}=\frac{v_{o n}}{v_{i n}}, \\
R_{t}=\frac{v_{o t}}{v_{i t}} .
\end{array}\right.
$$

Literatures $[14,15]$ show the effect of various surface coverings on the restitution factor. Because the mine slope is a natural slope and its surface is covered with vegetation, $R_{n}$ and $R_{t}$ can be set as follows according to Table 1 .

$$
\left\{\begin{array}{l}
R_{n}=0.27, \\
R_{t}=0.80 .
\end{array}\right.
$$

3.2. Rolling Stone Falling Process Velocity Calculation. In the previous literature [16], the slope model, explosion area, and protection net have been built into a system. In order to study the throwing velocity of flying objects on the free surface of loose blasting in open-pit steps, four Gaussian points were set at the corresponding free surface of slope top, charge top, charge middle, and charge bottom, respectively (as shown in Figure 4), and the velocity characteristics of flying objects formed at these positions were analyzed. Through numerical simulation, the initial velocities of the four feature points on the step are as follows.

$$
\begin{aligned}
& \left\{\begin{array}{l}
v_{1 x}=-0.10 \mathrm{~m} / \mathrm{s}, \\
v_{1 y}=-4.86 \mathrm{~m} / \mathrm{s},
\end{array}\right. \\
& \left\{\begin{array}{l}
v_{2 x}=6.17 \mathrm{~m} / \mathrm{s}, \\
v_{2 y}=-2.53 \mathrm{~m} / \mathrm{s},
\end{array}\right. \\
& \left\{\begin{array}{l}
v_{3 x}=4.29 \mathrm{~m} / \mathrm{s}, \\
v_{3 y}=-1.14 \mathrm{~m} / \mathrm{s},
\end{array}\right. \\
& \left\{\begin{array}{l}
v_{4 x}=2.42 \mathrm{~m} / \mathrm{s}, \\
v_{4 y}=-0.59 \mathrm{~m} / \mathrm{s} .
\end{array}\right.
\end{aligned}
$$

Combined with the correlation between the parabolic motion and the velocity of the above four feature points, it is concluded that the flying objects with a long flight distance may appear in the area near the second feature point. In order to simplify the research process, the second feature point is taken as the research object. According to Newton's second law and momentum theorem, the position and velocity of the first collision between the flying object and the slope are obtained as follows:

$$
\left\{\begin{array}{l}
x_{1}=12.45 \\
y_{1}=14.83
\end{array}\right.
$$

According to equation (8), the normal velocity and tangential velocity of the flying object before the first collision with the hillside can be obtained as follows:

$$
\left\{\begin{array}{l}
v_{i t(1)}=17.17 \mathrm{~m} / \mathrm{s}, \\
v_{i n(1)}=6.35 \mathrm{~m} / \mathrm{s} .
\end{array}\right.
$$

According to the above calculation, after impact and reflection of the slope, the tangential velocity and normal velocity after the first interaction between the flying object and the slope are as follows: 

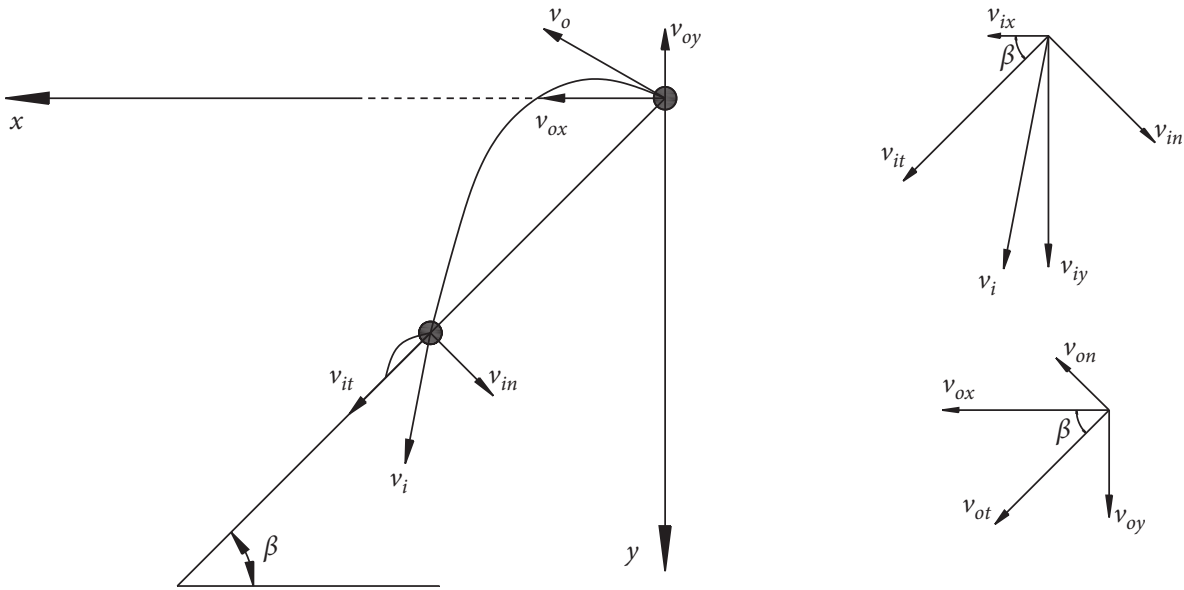

Figure 3: Schematic diagram of the velocity of the flying dispersion.

TABLE 1: Recovery coefficients under different surface conditions.

\begin{tabular}{lcc}
\hline Ground cover & Normal recovery factor $R_{n}$ & Tangential recovery coefficient $R_{t}$ \\
\hline Smooth and hard surfaces and paving surfaces & $0.37 \sim 0.42$ & $0.87 \sim 0.92$ \\
Mostly slopes in bedrock and conglomerate areas & $0.33 \sim 0.37$ & $0.83 \sim 0.87$ \\
Hard soil slopes & $0.30 \sim 0.33$ & - \\
Soft soil slopes & $0.28 \sim 0.30$ & - \\
Slopes with vegetation cover & $0.25 \sim 0.28$ & $0.80 \sim 0.83$ \\
\hline
\end{tabular}

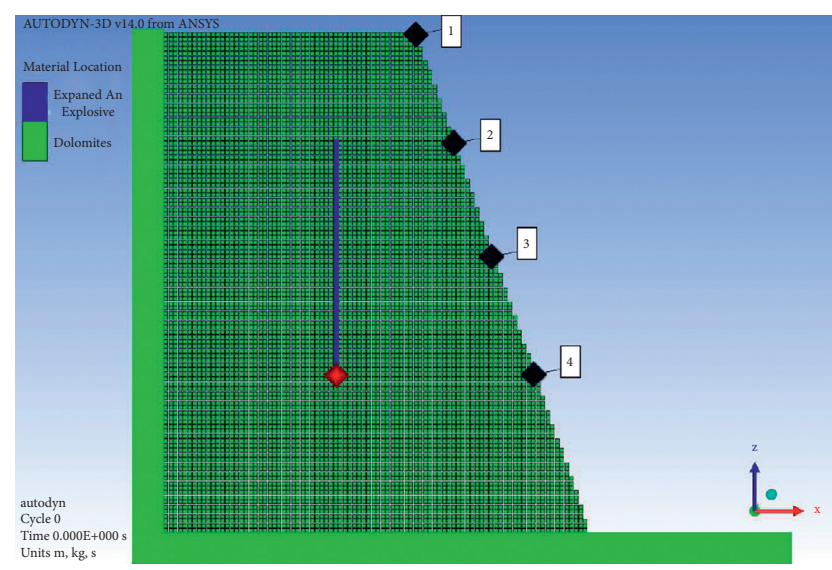

FIgURE 4: Diagram of the location of gauss point.

$$
\left\{\begin{array}{l}
v_{o t(1)}=13.74 \mathrm{~m} / \mathrm{s}, \\
v_{o n(1)}=1.71 \mathrm{~m} / \mathrm{s} .
\end{array}\right.
$$

After the blasting flyrock colliding with the slope and rebounded, the equations of horizontal and vertical velocity can be obtained according to the vectorial relationship of velocity as follows:

$$
\left\{\begin{array}{l}
v_{o x}=v_{o t} \cos \beta+v_{o n} \sin \beta, \\
v_{o y}=v_{o t} \sin \beta-v_{o n} \cos \beta .
\end{array}\right.
$$

After ignoring the air resistance, after the collision and rebound with the slope, blasting flyrock still meets the law of projectile movement under the action of gravity. After the second interaction between the blasting flyrock and the slope, the location and velocity can be obtained:

$$
\begin{aligned}
& \left\{\begin{array}{l}
x^{\prime}=17.97, \\
y^{\prime}=21.41,
\end{array}\right. \\
& \left\{\begin{array}{l}
v_{o t}^{\prime}=14.26 \mathrm{~m} / \mathrm{s}, \\
v_{o n}^{\prime}=0.46 \mathrm{~m} / \mathrm{s} .
\end{array}\right.
\end{aligned}
$$

By comparing the results, it can be known that after the second collision, the reflected tangential velocity is not very different from that of the first collision, while the reflected normal velocity is significantly less than that of the first collision. Gao and $\mathrm{Hu}$ [21] pointed out that the bounce of the blasting flyrock was up to 2 or 3 times. Therefore, in this study, it can be considered that after the second collision, the blasting flyrock moves along the slope at the initial velocity of the tangential velocity to form a rockfall.

The movement of falling rock on the slope can be simplified into a process of resisting friction between the rock and slope [14]. The following formula can be derived from the principle of conservation of energy:

$$
\sum m g \Delta h_{i}=\frac{1}{2} m\left(v_{i}^{2}-v_{o}^{2}\right)+\sum m g \cos \beta_{i} \cdot \tan \phi_{i} \cdot L_{i}
$$

where $\Delta h_{i}$ is the descending height of the rolling stone. Take $\Delta h_{i}=50 \mathrm{~m}-21.41 \mathrm{~m}=28.59 \mathrm{~m}$ according to the position of the second collision and the installation distance of adjacent protective nets; $v_{o}$ is the initial velocity of the interaction 
between the rockfall and the slope, $v_{0}=v_{0 t}^{\prime}=14.26 \mathrm{~m} / \mathrm{s} ; v_{i}$ is the velocity of rockfall at any point of the slope, $\mathrm{m} / \mathrm{s} ; \beta_{i}$ is the average angle of the slope, $50^{\circ} ; \varphi_{i}$ is the comprehensive friction angle of rockfall and the slope, which can be calculated according to the average increase angle of $1^{\circ}$; and $L_{i}$ is the sum of the length of the ramp segments before the rockfall contact with the protective net, $37.32 \mathrm{~m}$.

The velocity when rockfall contact with the protective net can be calculated by equation (11) is as follows:

$$
v_{i}=13.20 \mathrm{~m} / \mathrm{s} \text {. }
$$

\section{Numerical Simulation of the Interaction between Rockfall and Protective Net}

\subsection{Material Selection and Constitutive Relationship}

4.1.1. Rock Material. Based on the above assumptions, the second fragmentation of the rock is not considered during the rolling process. Therefore, the rock can be defined as a rigid body without considering the strength and failure parameters of the rock during numerical simulation.

4.1.2. Protective Net Material and the Choice of the Constitutive Relationship. During the interaction between rockfall with protective net, elastic, plastic deformation, and even failure will occur, which should be taken into account in this study. It is shown that the Cowper-Symonds constitutive model can simulate the deformation and damage of wire ropes well [22-24].

The model takes into account the plastic strain effect of the material and is applicable to the case where the change rate of the material strain during the collision is large, and in the calculation, the yield stress is expressed in terms of factors related to the strain rate.

$$
\sigma_{y}=\left[1+\left(\frac{\varepsilon}{C}\right)^{1 / p}\right]\left(\sigma_{0}+\beta E_{p} \varepsilon_{p}^{\text {eff }}\right),
$$

where $\sigma_{y}$ is the yield stress considering the effect of strain rate; $\sigma_{0}$ is the initial yield stress; $\varepsilon$ and $\varepsilon_{p}^{\text {eff }}$ are the strain rate and effective plastic strain, respectively; $E_{p}$ is the plastic hardening modulus; and $C$ and $P$ are the Cowper-Symonds strain rate parameters, for steel can be taken as follows: $C=40$ and $P=5$, respectively.

According to the protective net in this project, rock and wire rope parameters were determined and are shown in Table 2.

While contacting with the rockfall, the integrity of the protective net depends mainly on its geometric dimension, the kinetic energy of rock, the size of rockfall, and many other factors. Referring to the passive protective net in this project, a numerical model was established to study the interaction between the rock and the protective net from the above three perspectives.
4.2. Model Analysis and Construction. In order to prevent the blasting individual flyers from rolling down the southeast side slope and affecting the villagers' life at the foot of the slope, there is passive protection netting installed on the southeast side slope at a certain distance, which adopts the SNS passive flexible protection netting system (Safety Netting System), the net type is DO/07/300 type wire rope netting, the mesh size is about $300 \mathrm{~mm}$, and the mesh is connected by a single ROCCO ring nested between the holes, as shown in Figure 2. Under the action of the protective net, the rolling stone decelerates, rebounds, and consumes a lot of energy; thus, the secondary rebound collision between the rock and the protective net is no longer considered.

While establishing the numerical model, the grid mesh can be simplified to rhombus for simplifying the modeling analysis, and the nesting between the rhombus can be replaced by a common node among the rhombuses, so there are no relative sliding between the rhombus mesh, and the contact between the mesh and the support rope can be considered as no-slip contact. Rockfall and protective net collision process do not consider the disintegration due to the process of mutual collision of rocks and protective net; for the convenience of modeling, the rockfall will be simplified to a sphere, and rockfall and protective net collision velocity is $13.20 \mathrm{~m} / \mathrm{s}$. Since the preprocessing function of the AUTODYN finite element analysis program is more difficult to build complex models, the model is built by first using LS-DYNA for a series of tasks such as model building, algorithm selection, and definition of contacts and then importing the * ${ }^{*} \mathrm{~K}$ file generated by LS-DYNA into AUTODYN and setting the unit system of operation as $\mathrm{m}, \mathrm{kg}$, and s. LS- DYNA modeling effect and the modeling effect after importing AUTODYN are shown in Figure 5.

\subsection{The Impact of the Geometric Dimension of the Protective} Net on the Protective Effect. Some passive protective nets were installed on the southeast side of the slope of the MALU phosphate mine; the height of the protective net is $4.0 \mathrm{~m}$, and the distance between two adjacent steel columns is $10.0 \mathrm{~m}$. In order to study the impact of the geometric dimension of the protective net on the protective effect, the models of protective nets with the geometric dimension of $4.2 \mathrm{~m} \times 4.2 \mathrm{~m}$ and $6.0 \mathrm{~m} \times 6.0 \mathrm{~m}$ were established, respectively. The initial velocity of the rockfall was set as $15.0 \mathrm{~m} / \mathrm{s}$. The energy-time curve and the velocity-time curve of the rockfall were calculated and are shown in Figures 6 and 7, respectively.

It can be seen that at the same initial velocity of $15.0 \mathrm{~m} / \mathrm{s}$, the smaller the size of the protective net, the longer the interacting buffer time. According to the momentum theory $f t=m v$, it can be known that the smaller the size of the protective net, the shorter the interaction time between the rockfall and the protective net, and the greater the impact of the rockfall on the protective net.

4.4. The Impact of Rockfall's Kinetic Energy on the Protective Effect. Consider the length and height of the actual protection net are $10.0 \mathrm{~m}$ and $4.0 \mathrm{~m}$, respectively; the model of 
TABle 2: Material parameters table.

\begin{tabular}{lcccccc}
\hline Material name & Density $\left(\mathrm{kg} / \mathrm{m}^{3}\right)$ & Bulk modulus $(\mathrm{GPa})$ & Shear modulus $(\mathrm{GPa})$ & Yield stress $(\mathrm{GPa})$ & Hardening index & Failure strain \\
\hline Rock & 2750 & 14.42 & 19.97 & - & - & - \\
Protective net & 7850 & 166.67 & 76.92 & 1.77 & 1 & 0.05 \\
\hline
\end{tabular}

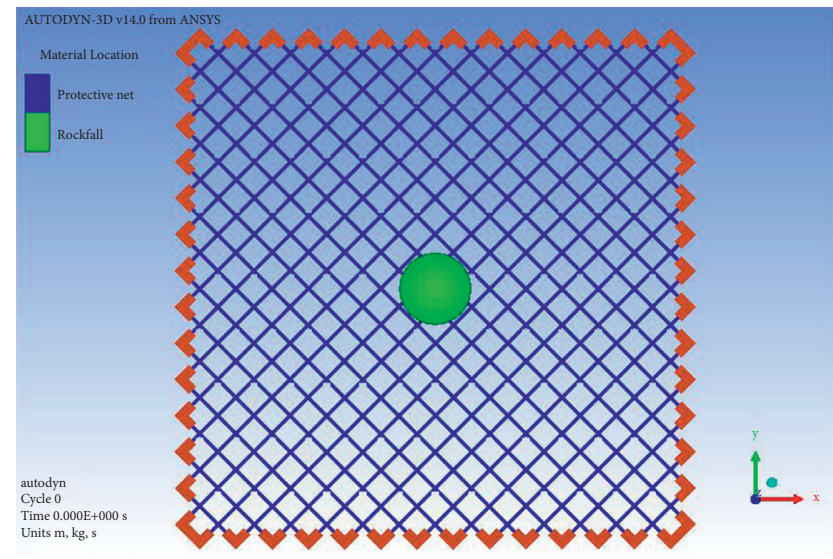

(a)

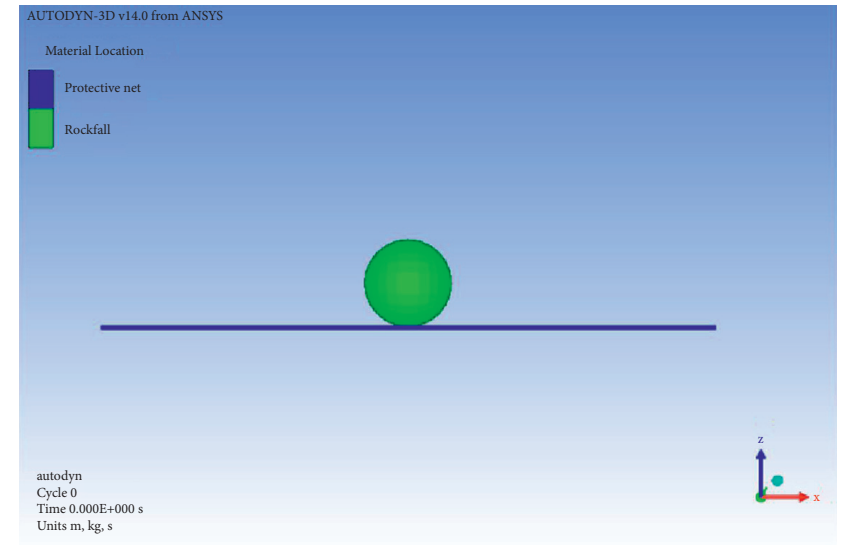

(b)

Figure 5: Modeling effect: (a) AUTODYN top view; (b) AUTODYN main view.

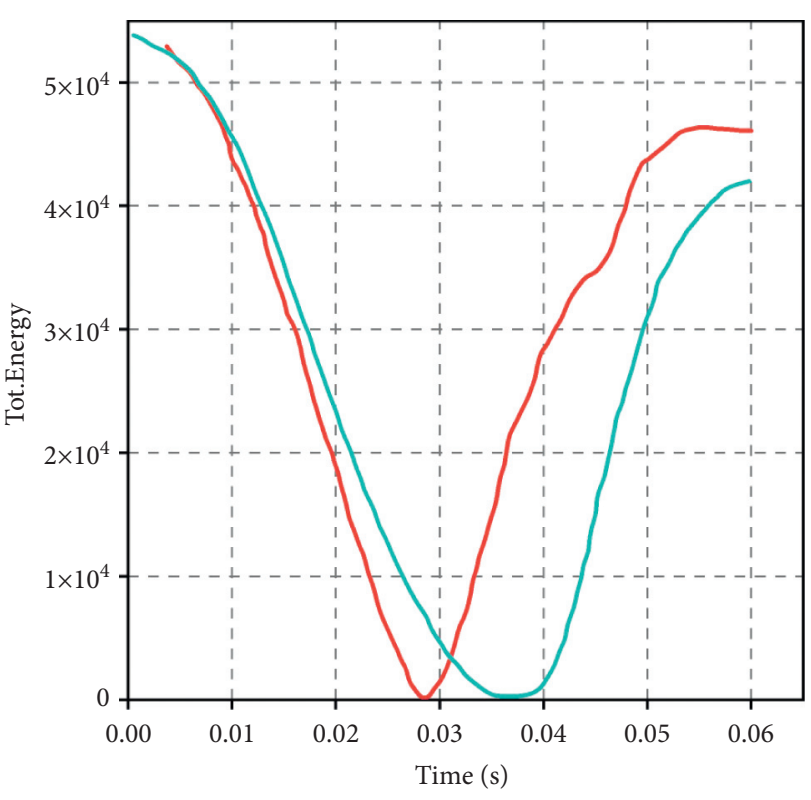

- (1) Ident $1-4.2 \mathrm{~m} \times 4.2 \mathrm{~m}$

- (2) Ident 2-6.0 $\mathrm{m} \times 6.0 \mathrm{~m}$

FIGURE 6: Energy-time curve of rock fall $\left(v_{0}=15.0 \mathrm{~m} / \mathrm{s}\right)$.

the protective net was conservatively defined as $4.2 \mathrm{~m} \times 4.2 \mathrm{~m}$, and the rockfall was modeled as a sphere with the diameter of $0.7 \mathrm{~m}$; the initial velocity $v_{0}$ of the rockfall was set as $12.0 \sim 18.0 \mathrm{~m} / \mathrm{s}$ while studying the effects between rockfalls with different kinetic energy and the protective net. The energy and the velocity-time curve of the interaction between the rockfall and the protective net are shown in Figures 8 and 9.

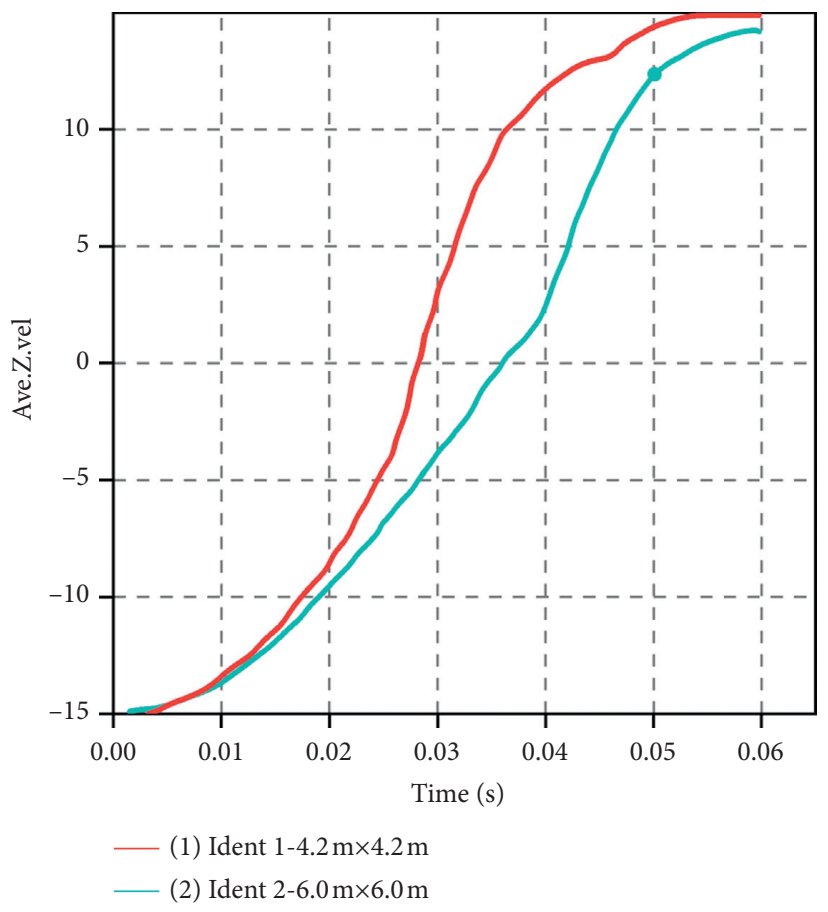

Figure 7: Velocity-time curve of rock fall $\left(v_{0}=15.0 \mathrm{~m} / \mathrm{s}\right)$.

It can be seen that when the mesh size and the size of the rockfall were fixed according to the momentum theory, the greater the rockfall kinetic energy, the shorter the interaction time between rock and net, and the greater the impact of the protective net. When the diameter of rockfall was $0.7 \mathrm{~m}$, the impact velocity was $18.0 \mathrm{~m} / \mathrm{s}$, the energy curve of the rockfall turned before it dropped to zero, indicating that the protective net was damaged, and the destruction process is 


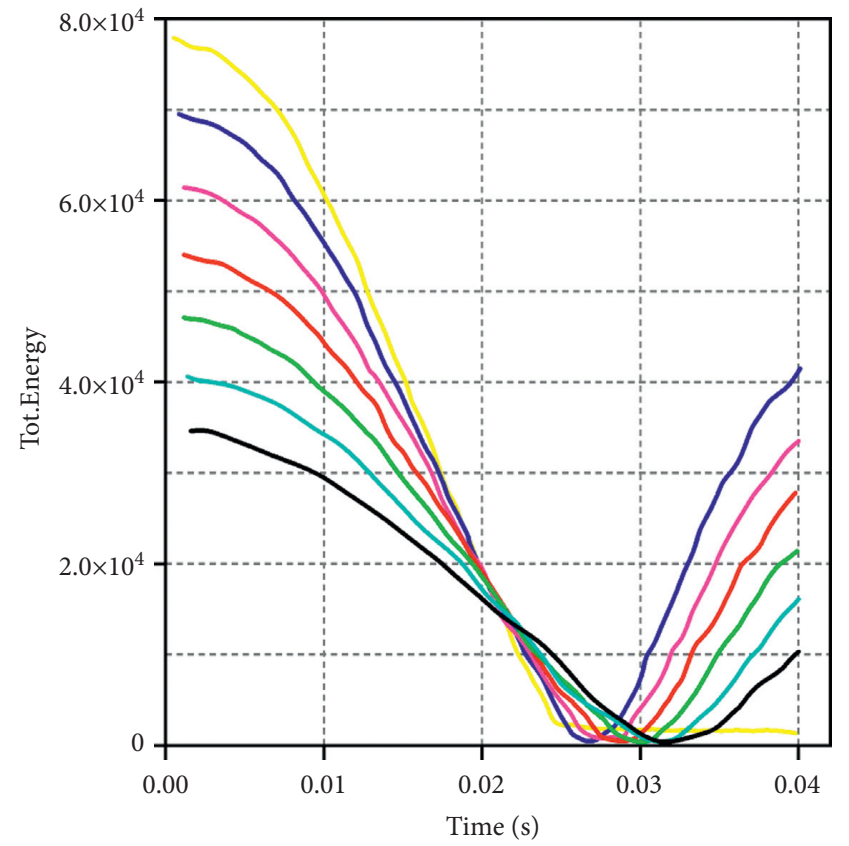

(1) Ident $1-12 \mathrm{~m} / \mathrm{s}$
(2) Ident $2-13 \mathrm{~m} / \mathrm{s}$
(3) Ident $3-14 \mathrm{~m} / \mathrm{s}$
(3) Ident $5-16 \mathrm{~m} / \mathrm{s}$
(4) Ident $4-15 \mathrm{~m} / \mathrm{s}$

Figure 8: Energy-time curve of rockfall.

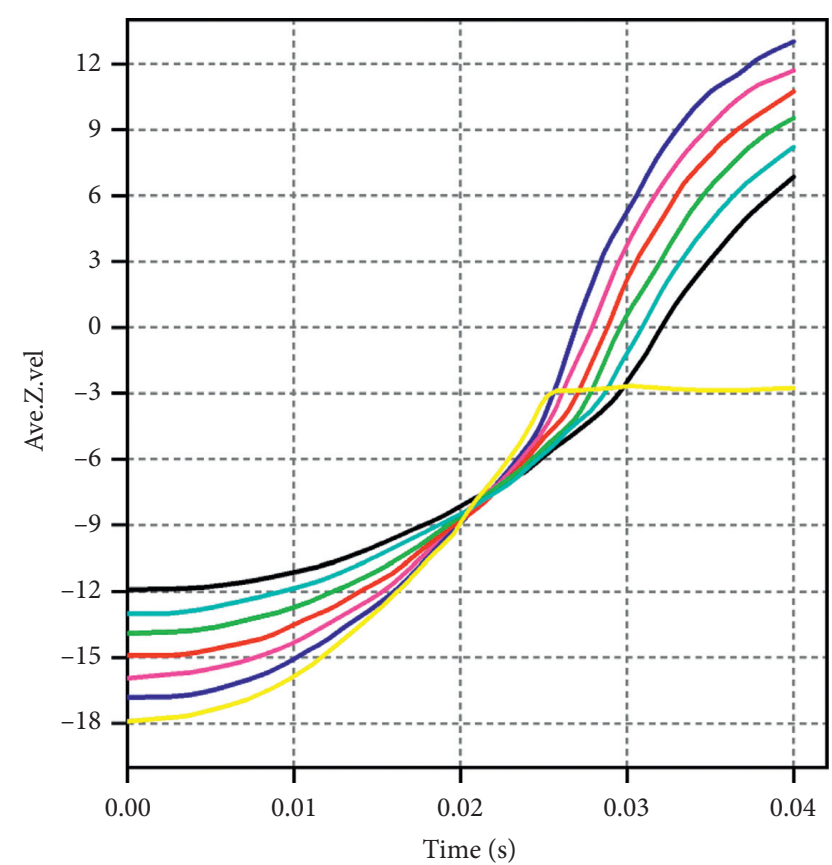

- (1) Ident $1-12 \mathrm{~m} / \mathrm{s}$

(5) Ident $5-16 \mathrm{~m} / \mathrm{s}$

— (2) Ident $2-13 \mathrm{~m} / \mathrm{s}$

(6) Ident $6-17 \mathrm{~m} / \mathrm{s}$

(3) Ident $3-14 \mathrm{~m} / \mathrm{s}$

- (4) Ident $4-15 \mathrm{~m} / \mathrm{s}$

(7) Ident $7-18 \mathrm{~m} / \mathrm{s}$

Figure 9: Velocity-time curve of rockfall. shown in Figure 10. Also, it can be known that when $t=25 \mathrm{~ms}$, the protective net was damaged under the impact of rockfall, and the damaged position is shown in Figure 10(d).

4.5. The Impact of Rockfall's Size on the Protective Effect. While studying the impact of rockfall size on the protective effect, the initial kinetic energy of the rockfall and the size of the protective net were set as a constant. The size of the protective net model was $4.2 \mathrm{~m} \times 4.2 \mathrm{~m}$, the diameter of the rockfall was set as $0.4 \mathrm{~m}, 0.5 \mathrm{~m}, 0.6 \mathrm{~m}$, and $0.7 \mathrm{~m}$, respectively, and the initial kinetic energy was $54.6 \mathrm{~kJ}$. While it was interacting with the protective net, the variation curve of energy of rockfall with different diameters for the same initial kinetic energy was obtained and is shown in Figure 11.

It can be seen that under the condition of the same kinetic energy, the smaller diameter of the rockfall can attenuate the energy rapidly under the action of the protective net, the buffer time is shorter, and the impact of the protection network will be greater. This phenomenon can be explained as that the larger the forced area, the more scattered force that the protective net suffered, and the longer the buffer time between the rockfall and the protective net.

\section{Safety Analysis}

In order to understand the characteristics of the movement of the rock on the slope, several tests were conducted on-site. The experimental results showed that the initial kinetic energy of rockfall with small size was small in the rolling process, and the rockfall stopped soon because of the resistance of the slope during the rolling along the slope.

Through the field investigation of the rockfall on the southeast side slope of the MALU phosphate mine, it is found that there is basically no large flying rock produced in the blasting process, and the movement of the smaller flying rock is stopped under the effect of its collision with the slope, and the range of individual rockfall rolling down the slope is mostly between $0.3 \mathrm{~m}$ and $0.5 \mathrm{~m}$ (Figure 12). Based on the calculation results of the rockfall movement in Section 2, the instantaneous velocity before the interaction between the rockfall and the protective net was determined to be $13.2 \mathrm{~m} / \mathrm{s}$. The simulation results show that the protective net was damaged when the diameter of rockfall was $0.7 \mathrm{~m}$ and the impact velocity was close to $18.0 \mathrm{~m} / \mathrm{s}$. The comparison shows that the passive protective net set can sufficiently sustain the impact of rockfall formed by blasting flyrock, and the normal blasting operation of the mine does not influence the village on the southeast foot.

\section{Discussion}

The assumptions set in this paper are only used in the present study, such as assumptions (2) and (4). In fact, there are many angles and locations of collision, and it is impossible to test them one by one in the paper, and only specific conditions are set for analysis. Even if there is a collision between flying stones, as the falling stones and 


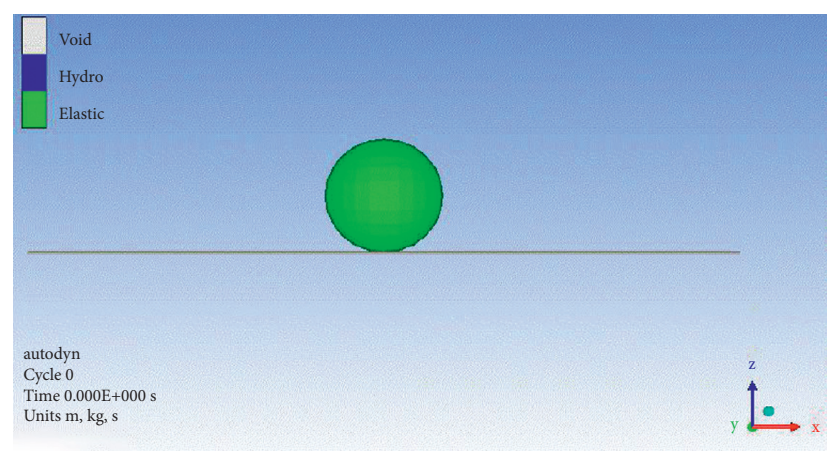

(a)

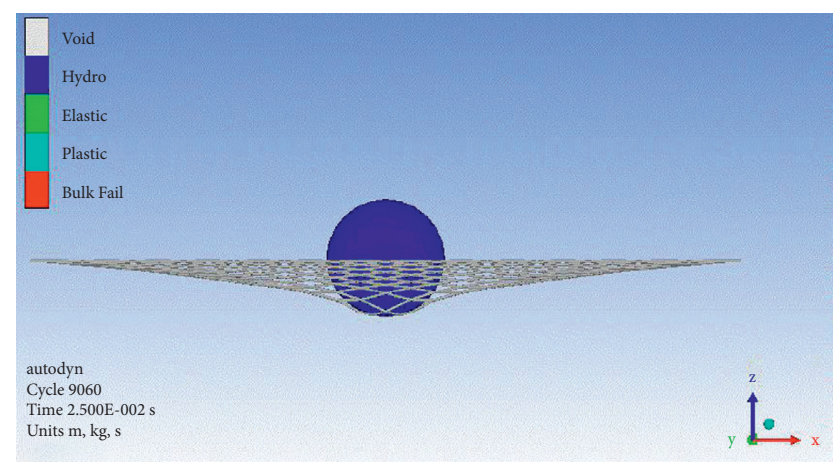

(c)

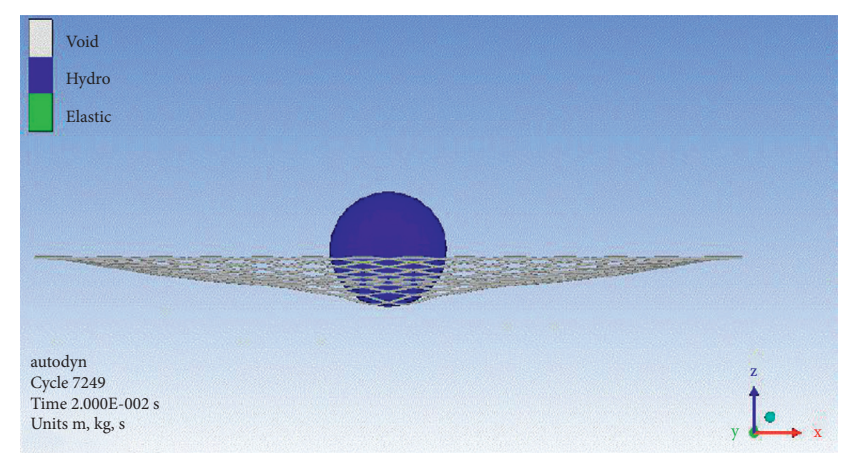

(b)

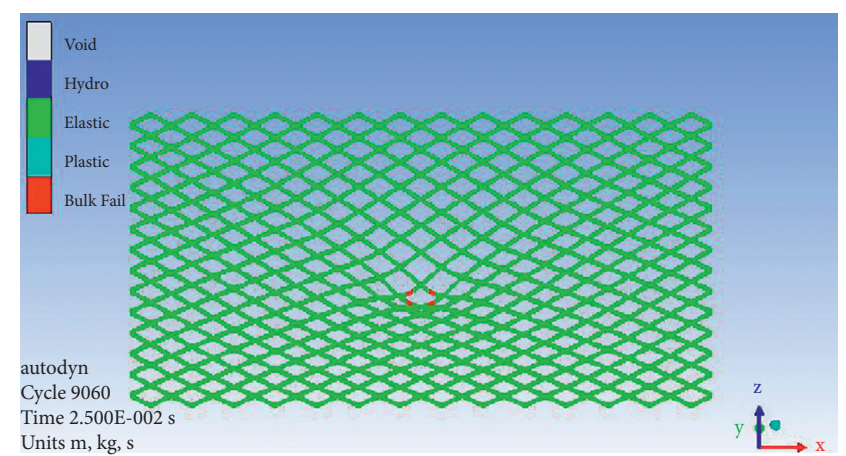

(d)

FIGURE 10: The process and location of the collision between rockfall and protective net: (a) $t=0 \mathrm{~ms}$; (b) $t=20 \mathrm{~ms}$; (c) $t=25 \mathrm{~ms}$; (d) damaged-location of protective net.

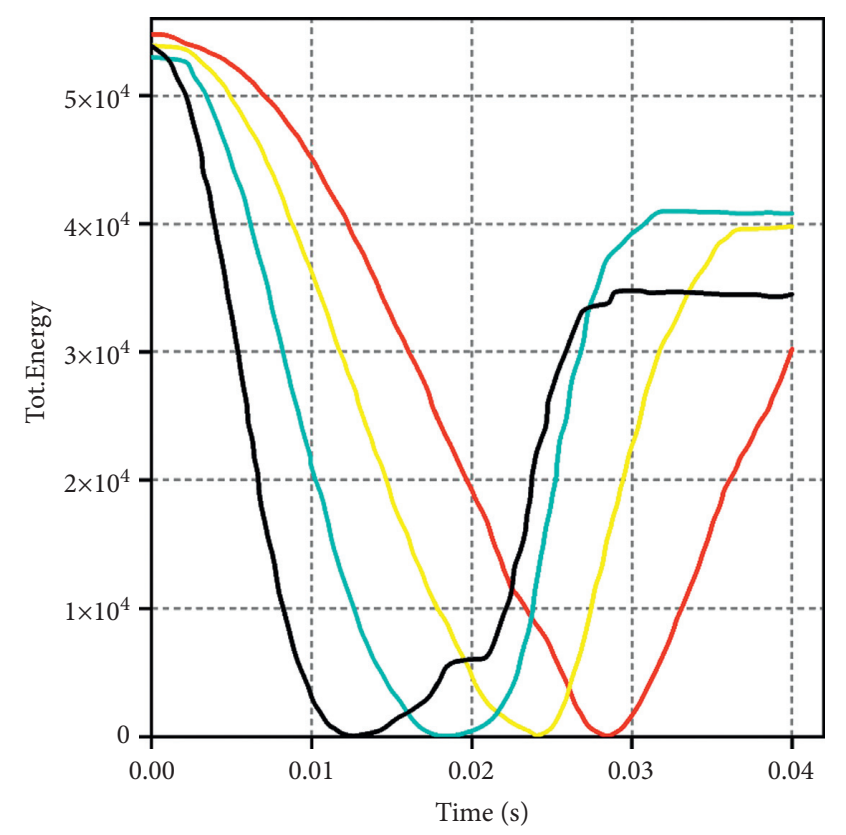

$\begin{array}{rr}\text { (1) Ident } 1-0.4 \mathrm{~m} & \text { (3) Ident 3-0.6 m } \\ - \text { (2) Ident } 2-0.5 \mathrm{~m} & - \text { (4) Ident } 4-0.7 \mathrm{~m}\end{array}$

FIGURE 11: Energy-time curve of rockfall in the same initial kinetic energy.

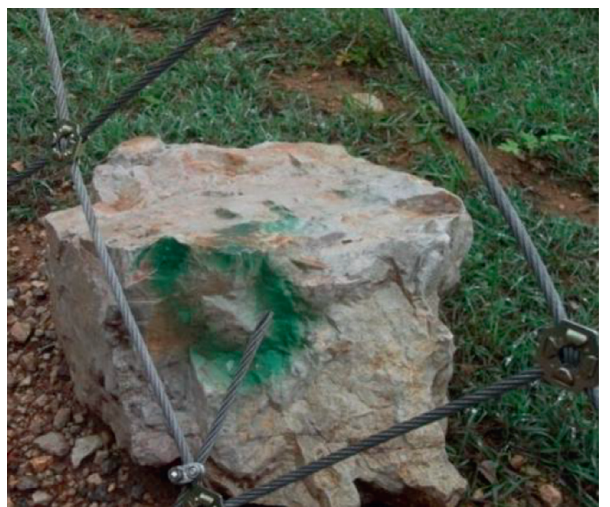

FIGURE 12: Rockfall formed by blasting flyrock.

slope broken into many pieces, it can still be considered as another rolling stone impact on the protection network. According to real engineering conditions, the numerical simulation analysis of the rockfall problem should be divided into two steps: first is the process of forming rolling stone by blasting at the top of slope; this part of the work has been already published (Reference [16]), so the assumptions of (5), (6), (7), and (8) can be proposed; then, the impact velocity of rolling stone is calculated according to Section 2 of this paper, and the impact process of rolling stone on the 
protective net is simulated under different impact velocities. The shape of flying stone has a certain influence on the protection effect. In rolling stones of similar volume, the circle is more difficult to protect; therefore, the assumption (9) is set up.

\section{Conclusions}

(1) Under the condition of the same kinetic energy and same size of rockfall, the larger the size of the protective net, the longer the buffer time, and the greater the impact of the protection net.

(2) Under the condition of the constant geometric dimension of the protective net and the size of the rockfall, the greater the rockfall kinetic energy (initial velocity), the shorter the buffer time in the interaction with the protective net, and the greater the impact force of the protection net.

(3) Under the condition of the same protective net size and the kinetic energy of rockfall, the larger the size of the rockfall, the larger the interaction area with the protective net, the longer the buffer time, and the less the impact force of the protection net.

(4) Through the comprehensive analysis of the movement characteristics of the rockfall formed by blast flyrock and the intercept ability of the protective net to the rockfall, it can be indicated that the normal blasting of the mine does not have impacts on the village on the southeast side of the mountain [25].

\section{Data Availability}

The data used to support the findings of this study are included within the article.

\section{Disclosure}

Qingyun Qian is the co-first author.

\section{Conflicts of Interest}

The authors declare that they have no conflicts of interest.

\section{Acknowledgments}

This research was supported by the National Natural Science Foundation of China (Grant no. 52064025).

\section{References}

[1] L. Q. Zhang, Z. F. Yang, and B. Xu, "Rock falls and rock fall hazards," Journal of Engineering Geology, vol. 12, no. 3, pp. 225-231, 2015, in Chinese.

[2] S. Wang, X. Li, J. Yao et al., "Experimental investigation of rock breakage by a conical pick and its application to nonexplosive mechanized mining in deep hard rock," International Journal of Rock Mechanics and Mining Sciences, vol. 122, Article ID 104063, 2019.

[3] X. Y. Zhou, A. R. Chen, and R. J. Ma, "Numerical simulation of energy dissipation mechanism on falling rocks protection nets," Journal of Chang'an University (Natural Science Edition), vol. 32, no. 6, pp. 59-66, 2012, in Chinese.

[4] D. Bozzolo and R. Pamini, "Simulation of rockfalls down a valleyside," Acta Mechanica, vol. 63, no. 1, pp. 113-130, 1986.

[5] D. Peila, S. Pelizza, and F. Sassudelli, "Evaluation of behavior of rockfall restraining nets by full scale tests," Rock Mechanics and Rock Engineering, vol. 31, no. 1, pp. 1-24, 1998.

[6] C. Thornton, Z. Ning, C. Y. Wu, M. Nasrullah, and L. Yuan, "Contact mechanics and coefficient of restitution," in Granular Gases, T. Poschel and S. Luding, Eds., pp. 184-194, Springer, Berlin, Germany, 2001.

[7] A. Cazzani, L. Mongiovi, and T. Frenez, "Dynamic finite element analysis of interceptive devices for falling rocks," International Journal of Rock Mechanics and Mining Sciences, vol. 39, no. 3, pp. 303-321, 2002.

[8] G. Gottardi and L. Govoni, "Full-scale modeling of falling rock protection barriers," Rock Mechanics and Rock Engineering, vol. 43, no. 3, pp. 261-274, 2010.

[9] M. Spadari, A. Giacomini, O. Buzzi, and J. Hambleton, "Prediction of bullet effect for rockfall barriers: a scaling approach," Rock Mechanics and Rock Engineering, vol. 45, no. 10, pp. 131-144, 2011.

[10] S. Q. Shi, M. Wang, and B. Sun, AUTODYN Dynamic Analysis of Engineering and Application Cases, China Architecture \& Building Press, Beijing, China, 2012.

[11] H. T. Hu, Collapse and Rockfall, China Railway publishing house, Beijing, China, 1998.

[12] Y. Q. Zhou and Y. K. Yang, "Flexible protecting systems of treatment dangerous slopes," Proceedings of Landslide in China, vol. Vol.14, China Railway publishing house, Beijing, China, 2000, in Chinese.

[13] M. Wang and Y. Y. K. ShiSQ, "Mechanical test and numerical simulation research on the slope active protection nets," Journal of civil, Architectural and Environment Engineering, vol. 33, no. S2, pp. 24-28, 2011, in Chinese.

[14] S. Q. Ye, H. M. Tang, and H. Zhu, "Design conception of safe net system based on analysis of motion trace of rockfall," Chinese Journal of Geotechnical Engineering, vol. 29, no. 4, pp. 566-571, 2007, in Chinese.

[15] S. Q. Xu, X. S. She, and S. C. Wang, "Free rolling model of stone on expressway slope," Journal of Traffic and Transportation Engineering, vol. 11, no. 2, pp. 14-17, 2011, in Chinese.

[16] Y. H. Huang, Z. L. Mao, Z. Y. Zhang, X. H. Li, and L. Yan, "Building the intelligent transportation systems based on the computation of driving velocity law of blasting fly-rock," Cluster Computing, vol. 22, no. S1, pp. 759-768, 2019.

[17] H. Xu, C. Gentilini, Z. Yu, X. Qi, and S. Zhao, “An energy allocation based design approach for flexible rockfall protection barriers," Engineering Structures, vol. 173, pp. 831-852, 2018.

[18] P. Yan, J. Zhang, X. Kong, and Q. Fang, "Numerical simulation of rockfall trajectory with consideration of arbitrary shapes of falling rocks and terrain," Computers and Geotechnics, vol. 122, Article ID 103511, 2020.

[19] L. Zhao, Z.-X. Yu, Y.-P. Liu, J.-W. He, S.-L. Chan, and S.-C. Zhao, "Numerical simulation of responses of flexible rockfall barriers under impact loading at different positions," Journal of Constructional Steel Research, vol. 167, Article ID 105953, 2020.

[20] Z. H. Zhu, J. H. Yin, J. Q. Qin, and D. Y. Tan, "A new discrete element model for simulating a flexible ring net barrier under rockfall impact comparing with large-scale physical model 
test data," Computers and Geotechnics, vol. 116, Article ID 103208, 2019.

[21] W. L. Gao and F. Hu, "The outer blasting study of blasting flyrock," Blasting, vol. 13, no. 1, pp. 12-15, 1996, in Chinese.

[22] Z. He, S. G. Zhao, J. L. Yang, and W. Cheng, "Experimental investigation of the dynamic material property of stainless steel:0Cr17Ni4Cu4Nb," Journal of Material Science \& Engineering, vol. 25, no. 3, pp. 418-421, 2007, in Chinese.

[23] Y. S. Zhao and X. M. Zhang, "Yield constitutive model of Al5.8Cu alloy," Material \& Heat Treatment, vol. 41, no. 4, pp. 55-57, 2012, in Chinese.

[24] X. Y. Liu, Dynamic Constitutive Relationship of TC4titanium alloy, Nanjing University of Aeronautics and Astronautics, Nanjing, China, 2010, in Chinese.

[25] S. Wang, L. Sun, X. Li et al., "Experimental investigation of cuttability improvement for hard rock fragmentation using conical cutter," International Journal of Geomechanics, vol. 21, no. 2, Article ID 06020039, 2021. 